watch the course of the patient. Cases of gastric hemorrhage entering the accident room should be seen as a rule by a physician as well as a surgeon. Operations upon females under thirty years of age should be most conservatively advised, since death under medical treatment is rare. This generalization, however, should not unduly influence consultants in a case of repeated hemorrhages threatening life, even in a patient below this age. Time should not be lost during an operation in seeking the bleeding point, but gastro-enterostomy should be performed.

(3) Mortality in operations for perforation of the stomach is chiefly dependent upon the length of time intervening between perforation and operation and the virulence of the infection. To lessen the mortality, house officers should report suspected cases simultaneously to the physician and surgeon on duty, or their substitutes, and should obtain permission for a possible operation from the patient or friends.

(4) Patients with chronic ulcers of the stomach or strictures of the pylorus should be jointly watched by the physician and surgeon. The surgeon should know the patient before being compelled to operate. Postponement of operation after it is indicated is dangerous, owing to the possibility of hemorrhage, perforation and exhaustion.

(5) Errors in surgical technique occurred, which in subsequent operations will presumably be avoided. Methods of operation were chosen which in the light of the experience of to-day would be considered unsuitable. Together these classes of cases account for about half of the deaths.

(6) The seventy-one cases were operated upon by twenty-five different surgeons - an average of one case to each surgeon in twenty-five months. It is reasonable to conclude that the mortality would have been less if each surgeon had had more experience.

\section{THE UNION OF THE TEACHINGS IN CYSTOSCOPY AND MICROSCOPY.}

BY FRANK M. JOHNSON, M.D., BOSTON.

Ax adage of an earlier time still rings with the same truth and its forcible meaning to-day. It was then the thought had birth that "in union there is strength." Thus from a medical standroint might its application be converted to carry out the peculiar characteristics of these two adjuvants in our investigation of the diseases of the bladder and the kidneys. It is not the intention at this time to enter into the minute details of the methods used, or descriptions of various instruments, but rather to bring perhaps miore forcibly to your attention and consideration the value of suggestions to be gained when in harmony the microscope and cystoscope can give to us more clean-cut and definite knowledge. Before instrumental interference is demanded or warranted, the wise procedure is to obtain a com- plete record from an exhaustive chemical and microscopical analysis of a specimen of urine. By this step a diagnosis is obtainable that will most likely approximate the conditions to be miet with.

From the number, condition and appearance of the epithelia present, the presence or absence of casts, mucus, red blood corpuscles, pus corpuscles, connective tissue shreds and the varied forms of erystalline and amorphous sediments, all these with the data of clinical history, in a certain case, will repay by the value of the deductions that are now far less difficult to surmise.

If a doubt might remain, it is then that the eystoscope will readily prove or disprove the microscopic findings. The tiny brilliant electric light, in conjunction with delicate lenses, gives to the observer vivid pictures and often clears up miysteries that were perplexing.

A growth is discovered that before gave no symptoms or signs of its existence. A clever instrument, lately devised by Dr. Follen Cabot of New York, eıables an operator to secure a small piece of such a growth, and then our microscope will reveal its nature, or a fragment of a calculus is caught up, and its composition soon determined. Again, with angular or straight observation telescopes, all parts of the bladder can be viewed. Various grades of inflammatory origin can be seen and exact conditions realized.

Now perhaps it is fairly said that the microscope first gives permission, and then may deniand the cystoscope as its aide-de-camp. May the day come, and that quickly, when such examinations as have been noted play their important parts in our routine practice; may our microscope receive the consideration that its teachings merit! No doubt a human life cannot nor will not last long enough to make the master of any person who may attempt to solve all the problems, all the riddles and all the kaleidoscopic transformations that lie within the minute drop -- under the fragile crystal. Errors arise due more ofter! to the lack of complete understanding on the part of the observer than to any fault that could possibly escape detection in a finely made instrument. Each and every object must meet with recognition, and relative values of the more important elements must have our careful consideration. The surgeon whose time is absorbed with many operations, the general practitioner who has no moments he may call his own, yes, even the successful follower of some special subject, js forced to rely upon some one else and accept his conclusions. The necessity of true, impartial, microsconic findings, however, will still constitute a factor of mighty value.

This same thought can apply again to the cystoscopic revelations. Both these measures require time, patience and a long experience. Can one in a pardonable enthusiasm overestimate their true worth? At the present time the most important rôle played by the microscope and cystoscope is in the examination of the kidneys. With the catheterization through the 
ureters, and the microscopical examinations of the separate urines, a vista of new thought is opened, whose field of usefulness is large and wide and whose possibilities are almost bevond comprehension. Here will it be found, that before a kidney is removed the surgeon must know the absolute conditions of both kidneys, or perhaps the lncation of a calculus or of growth in the bladder and its character. A very few out of the many doubtful phases may be dispelled by these methods of research from a surgical aspect. For a moment then, only lightly touching this phase, we turn to a large number of patients who apply for medicinal treatment for alleviation of their pains, distress and exhausted nervous conditions. When the true realization has not been granted to the physician, who certainly has done everything in his power, yet when medicinal remedial measures have been without avail in either giving nature a chance to cure, or of completely alleviating the stubborn syniptoms and their sequela - let it be said frankly and squarely that lavage of the pelves of the kidneys with appropriate medicated solutions given carefully and each change and effect noticed will, in the majority of our cases, either eradicate or certainly will ameliorate the disturbing influences created by a chronic pyelitis, or a pyelo-nephritis or cirrhosis, those of lithemia or an irritative oxaluria; these alone being simple examples of a thousand varied and comiplex conditions that may arise.

These few suggestions are offered with the hope that they will awaken a broader and keener interest, that they may appear worthy of deliberate consideration, and that each and every true student, who has devoted his life to a beloved cause, can, if he will, find helpful aid and gain a clearer vision from the keener sense of a better understanding through this union of thought in the teaching of these two most valuable and, may it be said, inseparable companions, - the microscope and cystoscope.

\section{Ulinical EDepartment.}

\section{A CASE OF UNIRADICULAR BRACHIAL PALSY AFFLCTING THE FIFTH CERVICAL NERVE.}

By John E. Donley, M.D., PRovidence.

The following case, which was referred to me by Dr. Frank H. Jackson, would seem to be worthy of record, since it probably represents a very rare palsy of the brachial plexus:

Miss C., a young woman of twenty, a book-binder by occupation, came under observation complaining of disability and of some pain in her left upper arm. Her family history is unimportant, except for the fact that her father suffers frequently from attacks of severe articular rheumatism. She herself has always enjoyed good health with the exception of an attack of malaria of one week's duration, five years ago, and her appearance in general is that of a well-nourished and healthy girl. On Easter Sunday, ten weeks before coming under observation, having exchanged heavy for light clothing, she took a long walk, and upon returning home complained of feeling very cold. Un Monday a sharp pain appeared in her left shoulder and neck, and by Tuesday it had become more severe, and was especially intense at night. By Wednesday it had extended as low as the elbow, and the arm was somewhat swollen from the shoulder to the elbowjoint. On Friday the pain had involved the forearm and fingers, and at the same time the right arm became swollen and painful from the shoulder to the elbow, this condition persisting for a week, when the pain and swelling in the right arm and left forearm disappeared rapidly and have not returned. A week after the beginning of the trouble she put her arm in a sling, in which she carried it for three weeks, and only at the end of this time was it noticed that there was inability to flex the forearm or to move the upper arm, although she cannot tell how long this disability had existed before she became aware of it. From the first she received constitutional treatment for rheumatism, and at the end of eight weeks came under the writer's attention, when the signs of disease were as follows: There was paralysis with atrophy of the left, s!npra- and infra-spinati, teres minor, deltoid, serratus magnus, both rhomboids and pectoralis major. These muscles did not react to faradism and gave quantitative changes to the galvanic current, contracting sluggishly to strong currents. The left biceps was perhaps a little weaker than the right, but showed no alteration to electrical stimulation. The atrophy in the deltoid, spinati, teres minor and rhomboids was severe. The scapula was winged, its lower angle approaching the vertebral column and its upper part being directed outward. The whole scapula was elevated. The acromion was uncovered and the head of the humerus had dropped from the glenoid cavity, an inch intervening between the acromion and the head of the bone. There were some thickening and adhesions about the joint, passive abduction and external rotation being partly restricted. There was no fluid in the joint. Voluntary abduction, external and internal rotation were absolutely impossible. The nerve trunks werc not tender in the arm, but firm pressure over the plexus above the clavicle gave tenderness. There had never at any time been tingling, numbness or other paresthesia, nor had there been herpes zoster or any variety of skin eruption. Sensation was everywhere normal except over the lower deltoid region, where there was some blunting of sensibility to pain, tactile and thermal stimuli, the defect, however, not beir.g marked. No affection of the brachialis anticus, supinator longus, triceps, subscapulasis or diaphragm could be discovered. There was no sign of disease in heart, lungs or other viscera.

Although we are acquainted with many cases of paralysis afferting several of the peripheral or proximal nerves, or as in the palsies of Erb and Klumpke, combined cords of the brachial plexus, the number of recorded cases in which the lesion has been limited to the individual spinal nerves is small, and the literature very meager.

Buzzard, in a recent article in "Brain," remarks upon the infrequency with which uniradicular palsies are mientioned, even in the extensive monographs upon the subject, and he quotes from Duval and Guillain, Secretan and others, whose only reference to the subject consists in the statement that umiradicular palsies of the brachial plexus are exceedingly rare. In the same contribution, Buzzard reports six cases, 